\title{
El violín en la pintura \\ Estudio comparativo sobre la representación pictórica del violín en seis obras de Gaudenzio Ferrari y Raoul Dufy
}

\author{
CARMEN CASTAÑón JimÉNEZ
}

\section{PRELUDIO}

El violín en la pintura

«La música debiera llamarse hermana menor de la pintura»

Leonardo da Vinci

Tenemos manifestaciones de la música en el arte desde la Antigüedad. Para el pintor, la música existe como forma, color o textura de un instrumento, movimiento del intérprete o expresión en el rostro del intérprete y del público. Por su naturaleza invisible, precisa de un lenguaje alegórico, y puesto que las más de las veces se representa por medio de instrumentos musicales, estos adquieren distintos simbolismos.

En la pintura la clara supremacía de la familia de las cuerdas sobre el viento se explica posiblemente por motivos visuales más que sociales: su geometría hace al violín rey del estudio. El que muchos pintores de épocas diferentes, como Ingrés, Velázquez, Rafael, Delacroix o Matisse, hayan reflejado el violín en sus obras demuestra su inmortalidad como tema.

Pero que un pintor retrate un violín o un violinista no significa que conozca el instrumento en profundidad. Al estudiar este aspecto la diferencia entre un musicólogo y un iconógrafo radica en que aquel tratará la obra como un documento que refleja una realidad de la práctica musical, mientras que éste se preguntará por el marco social del género pictórico, las convenciones que encierra y cualquier significado simbólico.

Este trabajo pretende abordar el tema del violín en la pintura mediante el estudio comparativo de seis obras; tres de Gaudenzio Ferrari y tres de Raoul Dufy. Como violinista, el violín en la pintura llama mi atención al 
tiempo que dicha formación es una herramienta imprescindible en estudios como el presente. Aparte del interés personal, otros factores apuntan a la representación pictórica del violín como un tema interesante de investigación, aunque sólo fuera por la clara preferencia que varios artistas le han dado en sus obras a lo largo de la historia. Más aún, se ha hecho alusión a la relación entre el violín y algunos utensilios de la pintura: el arco como pincel o el violín como paleta. Su unión provoca nuestro placer al contemplar el resultado de tal simbiosis.

\section{OBERTURA}

\section{Dos artistas}

Gaudenzio Ferrari y Raoul Dufy son dos pintores diferentes que retrataron violines durante su carrera artística. Sus visiones del violín no son opuestas, y si un hombre renacentista y un contemporáneo son capaces de enfocar un tema similarmente, podemos pensar que música y pintura se relacionan. Aun con todo, sus interpretaciones varían una respecto de la otra. Su tratamiento del violín, bien como un objeto, bien como criatura animada, nos proporciona el punto de partida para la comparación. El esbozo biográfico resulta imprescindible para comprender sus actitudes.

El maestro de los frescos en Vercelli ha sido llamado el Miguel Ángel de la escuela lombarda, pues Gaudenzio Ferrari (1470-1546) ha sido muy probablemente el artista con mayor fuerza y originalidad que dio esa escuela. Tuvo una larga y fecunda vida, si bien sus obras maestras están en pequeños pueblos de la Lombardia, fuera de las rutas turísticas, lo que explica la falta de familiaridad con su obra tanto por parte de estudiosos como del público en general. Parece ser que fue discípulo de Luini durante algún tiempo, y amigo de Rafael. En 1527 se trasladó a Milán, donde pintó frescos para iglesias. Las obras aquí estudiadas parecen datar de esta etapa.

Cercano en tiempo y lugar a los gigantes Leonardo y Bramante, logró y supo mantener una sorprendente originalidad e independencia. Sus frescos y demás pinturas se caracterizan por la viveza y variedad de la composición. Winternitz está convencido de la maestría de Ferrari como violinista y asegura que fue luthier ${ }^{1}$. Carecemos de pruebas, pero el co-

1 "There is no doubt that Gaudenzio had more than a profound interest in musical instruments; he must have been an expert player and, I am convinced, also a builder of instruments." 
nocimiento analítico de los instrumentos musicales que demuestra en su obra parecen apoyar esta hipótesis. Como hombre renacentista le interesaba el hombre y sus logros, considerando la música uno de los mayores. Sin embargo, la importancia de Ferrari en relación con el violín radica en que fue el primer pintor en retratar un violín con las características con que lo conocemos hoy. De hecho, los historiadores de la música toman su obra como referencia para investigar los oscuros orígenes del violín.

Cuatro siglos después vivió Raoul Dufy (1877-1953). En 1900 estuvo en la École des Beaux Arts en París, si bien parece ser que aborrecía el arte convencional de museo. Estaba fascinado por las yuxtaposiciones vibrantes de color características del Impresionismo y Postimpresionismo. Ya en 1907 había roto con la idea impresionista de color puro, acercándose a las tonalidades más intensas del fauvismo. Como buen fauve, buscaba la representación del movimiento constante de la vida, de ahí sus series sobre bailes populares, carreras de caballos, regatas, clubes sociales o conciertos. Desarrolló un estilo personal: color luminoso sobre un fondo blanco, con objetos esbozados con sensuales líneas ondulantes. Más tarde se dedicó al diseño de telas, cerámica y tapices. Aunque sus escenas de lujo y placer, de brillante colorido, no ejercieron influencia notable sobre ningún otro pintor, contribuyeron a popularizar el arte moderno, en especial el Fauvismo.

Dufy compartía con su familia el amor por la música. Dos de sus hermanos eran músicos profesionales y uno de ellos, crítico musical, le facilitaba entradas para conciertos. Entre sus amistades se encontraban varios célebres músicos como el director de orquesta Charles Munch y el cellista Pablo Casals ${ }^{2}$, aunque su vínculo más decisivo con el violín era su condición de violinista amateur: quería y comprendía el instrumento. Recuerda Munch:

«Conoci a Raoul Dufy en la década de los 30. Por aquella época acudía con frecuencia a los ensayos de la Orquesta del Conservatorio de París, que yo dirigía. Sin molestar, se sentaba en la última fila junto a Passerone, el famoso percusionista. Todavía le veo junto al órgano, inclinado sobre el papel, dibujando sin parar. Fue allí, entre nosotros los músicos, mientras ensayábamos nuestro programa, donde concibió sus series de Orquestas.» (En Guichard-Meili, 1964: 12)

\footnotetext{
"No cabe duda de que Gudenzio tenía un interés más que profundo por los instrumentos musicales; debió de ser un experto intérprete, y estoy convencido de que también construyó instrumentos». (Winternitz, 1979: 106).

2 CASALS llegó a decir que Dufy lograba una interpretación tan sutil de la música en su pintura, que él podía saber en qué tonalidad estaba escrita la pieza.
} 
A pesar de su amor por la música, sus violines carecen de importancia por sí solos. El tema predominante en su obra es la vida en sí misma y su movimiento.

¿Por qué comparar a Ferrari y a Dufy y no a otros? Existen varias razones:

- Ferrari fue probablemente el primer artista en pintar un violín, y Dufy es bastante reciente; el espacio de cuatro siglos proporciona un interesante intervalo para apreciar posibles divergencias.

- Los orígenes del violín nos llevan al siglo XV. El violín tal y como lo conocemos hoy ha evolucionado: Ferrari (S. XV) y Dufy $(S . X X)$ reflejan esta evolución.

- El cómo y el porqué los artistas se valen del violín en su obra también ha cambiado a lo largo del tiempo; las mentalidades de dos pintores relevantes en el campo y en su tiempo suponen un nuevo punto de comparación.

- El estudio comparativo, de dos pintores en este caso, debe apoyarse en modelos claramente diferenciados, que muestren desde el principio un tratamiento distinto del tema.

\section{INTERMEZZO (FUGA)}

Dos interpretaciones

Según Revilla (Revilla, 1990: 385), "las connotaciones de un violín en iconografía son siempre positivas, porque evoca sonidos dulces». Tanto Ferrari como Dufy hacen buena esta afirmación. Para poder comparar cómo tratan el violín en su obra se estudiarán tres de cada pintor y la comparación se apoyará en los siguientes criterios:

1) Cómo se representa el violín.

2) El propósito del artista.

3) Lo que significa para el artista.

4) Su papel en la obra.

5) Su papel en la composición global.

6) El contexto socio-cultural. 
De Gaudenzio Ferrari: La Madonna degli aranci (1529) (iglesia de San Cristoforo, Vercelli), Putto con instrumento de arco (fecha sin determinar) (Colección E. Schweitzer, Berlín), Adoración del Niño (fecha sin determinar) (Palazzo Reale, Turín).

De Raoul Dufy: El violinista (1937) (Colección Henri-Gaffié, Beaulieusur-Mer), El violinista (1945) (Colección Louis Carré, París), MozartConcierto (1951) (Colección Staatsgalerie, Stuttgart).

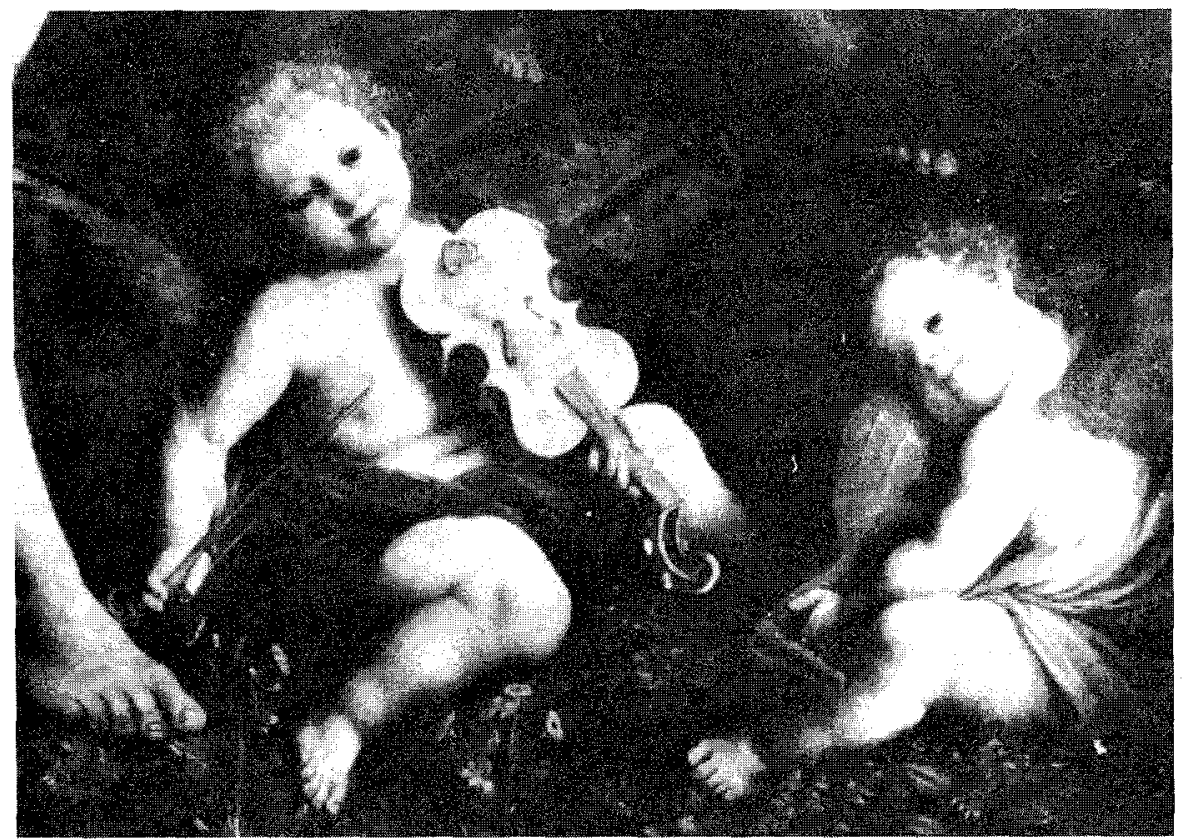

Lámina 1. Gaudenzio Ferrari (1470-1546). La Madonna degli aranci (detalle), 1529. Óleo sobre madera. Localización Iglesia de San Cristóforo, Vercelli (Italia).

Dos sonrientes angelotes ${ }^{3}$ tocan sendos instrumentos musicales. El de la izquierda sostiene un instrumento similar a un violín: cuerpo compacto, muy ancho, retratado casi como dos mitades simétricas. Se aprecia un cordal en forma de corazón y la voluta tiene tres clavijas (si bien la perspectiva permite una cuarta). La cabeza apunta hacia abajo, quizá porque el ángel no toca en ese momento, lo cual también explicaría la posi-

3 O amorini: las alas que demostrarían su condición de ángeles no están claras. 
ción del arco, fuera de la cuerda. El «violín» está colocado de forma estratégica dentro de la composición, de manera que todos sus detalles son visibles, incluso el bulto en la tabla.

La importancia de esta obra radica en contener claramente un pre-violín. El detalle con que está retratado nos indica que a Gaudenzio le interesa más una meticulosa descripción que una interpretación personal.

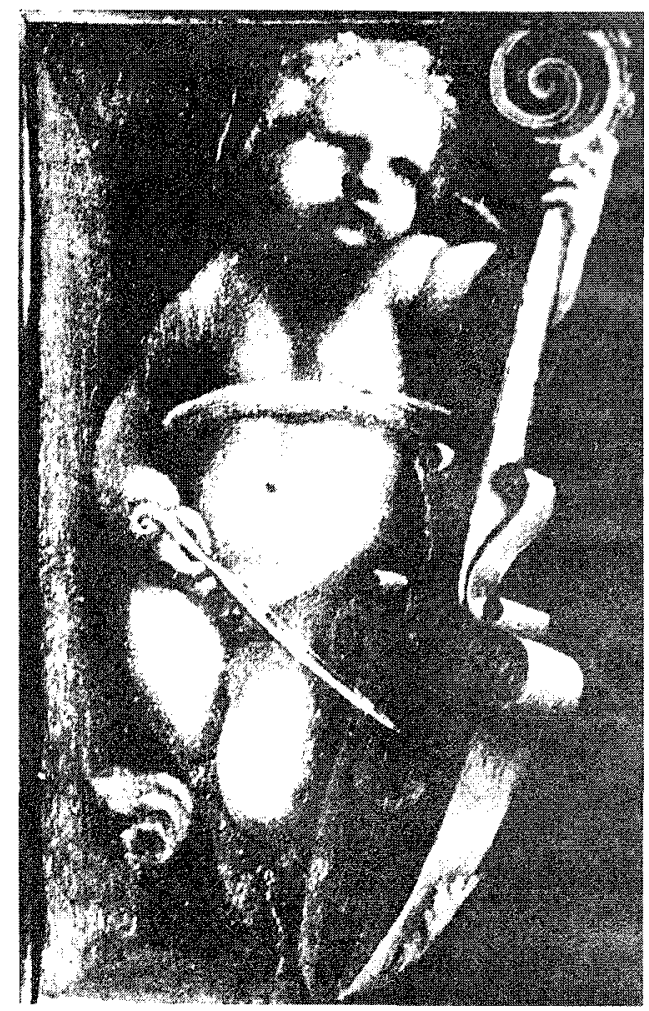

Lámina 2. Gaudenzio Ferrari (1470-1546). Putto con instrumento de arco, fecha sin determinar. Óleo sobre lienzo. Localización Colección E. Schweitzer, Berlín (Alemania).

Un putto o amor sostiene un extraño instrumento. Su cuerpo responde a los cánones imperantes en el tiempo de Ferrari: voluptuosidad y redondez de las carnes. El niño en sí es impersonal, y sin embargo su actitud tranquila transmite un sentido de belleza proporcionada que, al fin y al cabo, viene a ser la esencia del arte renacentista. Ferrari hace alarde aquí de su exuberante fantasia de forma, dotando al instrumento de un cuerpo picudo, ricas curvas, espirales, mango decorado con hojas talladas, dobles volutas en los hombros, reflejando la imagen de las efes... 
En esta pintura se hace patente el interés del hombre renacentista por la experimentación. Dado que el violín estaba evolucionando a grandes pasos en esa época, contribuciones como estas son valiosas, ya que nos proporcionan pistas sobre cómo se llevó a cabo esta evolución. Desde este punto de vista, podría considerarse la pintura un documento científico.

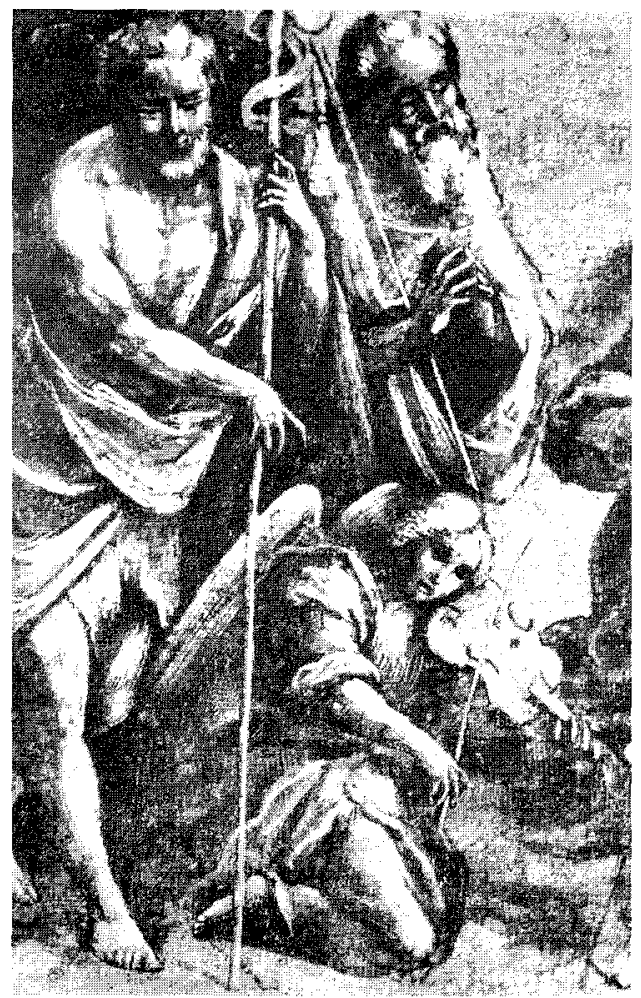

Lámina 3. Gaudenzio Ferrari (1470-1546). Adoración del Niño, fecha sin determinar. Óleo sobre lienzo. Localización Palazzo Reale, Turín (Italia).

Aparecen tres figuras en este cuadro: dos ancianos de pie y un ángel arrodillado tañendo un instrumento. Aquéllos disfrutan con los sones de éste, que parece concentrado en su ocupación a la vez que emocionado por el contexto: el Nacimiento del Mesías. El violín se presenta de cara arriba, transgrediendo toda perspectiva. Aunque las cuerdas no están pintadas, se intuyen cuatro, ya que el cordal no podría albergar más. La manera de coger el arco corresponde con lo que Jambe de Fer, el primer teórico del violín, parece haber dicho (Sadie, 1993: III, 249). De ahí que la técnica impresione como mala. El arco debería ir paralelo al puente según lo criterios actuales. 
La importancia de este cuadro radica en la confirmación de una forma existente en la época y ya encontrada en La Madonna degli aranci.

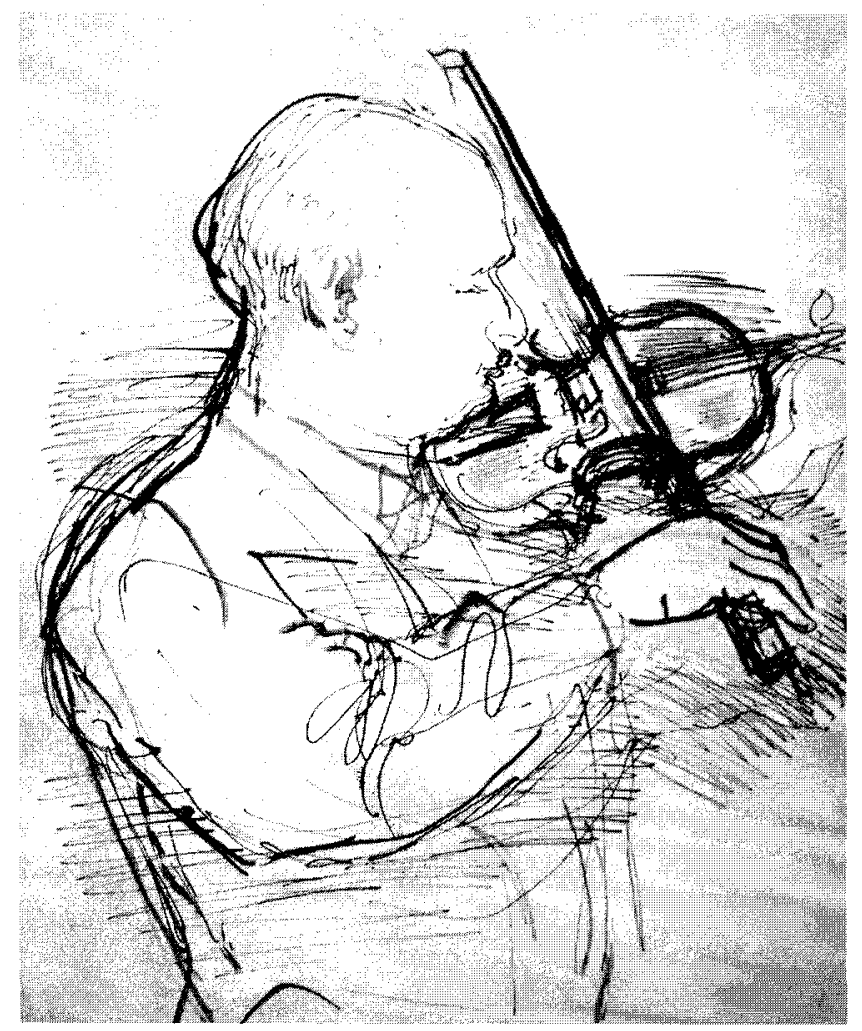

Lámina 4. Raoul Dufy (1877-1953). El violinista, 1937. Tinta y acuarela. Localización Colección Henri-Gaffié, Beaulieu-sur-Mer (Francia).

Asistimos en este retrato a la idea de Dufy violín-violinista. El intérprete, de pie (posición de estudio o solista), parece concentrado, si bien da más la impresión de preocupación técnica que musical. Su postura es correcta, fiel reflejo de la fina observación del artista y de su propia experiencia. Podría objetarse que la forma de agarrar el arco no es la más ortodoxa, pero, lejos de descalificar a Dufy como observador, juega a su favor: retrata la escuela francesa desvirtuada, con el meñique fuera de la nuez, ya que el arco va al talón.

Choca el tamaño del violín. ¿Por qué motivo dibujó Dufy un violín tan pequeño proporcionalmente cuando está más que claro que conoce la materia? Quizás la respuesta tenga que ver con su predilección por el Hombre más que por objetos. 


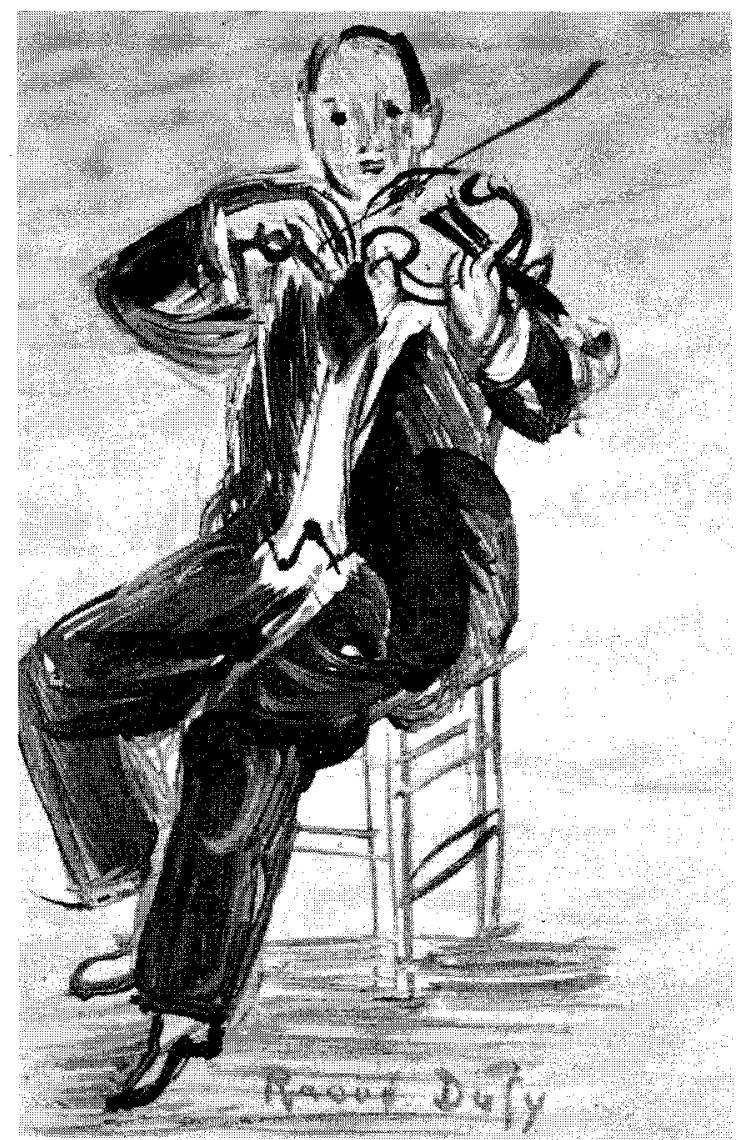

Lámina 5. Raoul Dufy (1877-1953). El violinista, 1945. Óleo sobre lienzo. Localización Colección Louis Carré.

Tenemos ante nosotros al mismo violinista que retrató en 1937, aunque aquí sedente. Posiblemente fuera miembro de la Orquesta del Conservatorio de París, a cuyos ensayos acudía Dufy regularmente.

Se aprecia claramente que se trata de un violinista, pero casi no hay detalles. La forma curva y el mango del violín nos dan la pista acerca del instrumento, ya que ni la voluta ni las efes ni las cuerdas aparecen pintadas. El arco se reduce a una recta que el violinista agarra de una forma no clara. La situación de la mano izquierda nos indica que está en una posición alta (sexta, séptima). Parece que Dufy a estas alturas ha abandonado el interés por la exactitud: la posición de ambos codos es demasiado elevada, dificultando seriamente el manejo práctico del instrumento. 


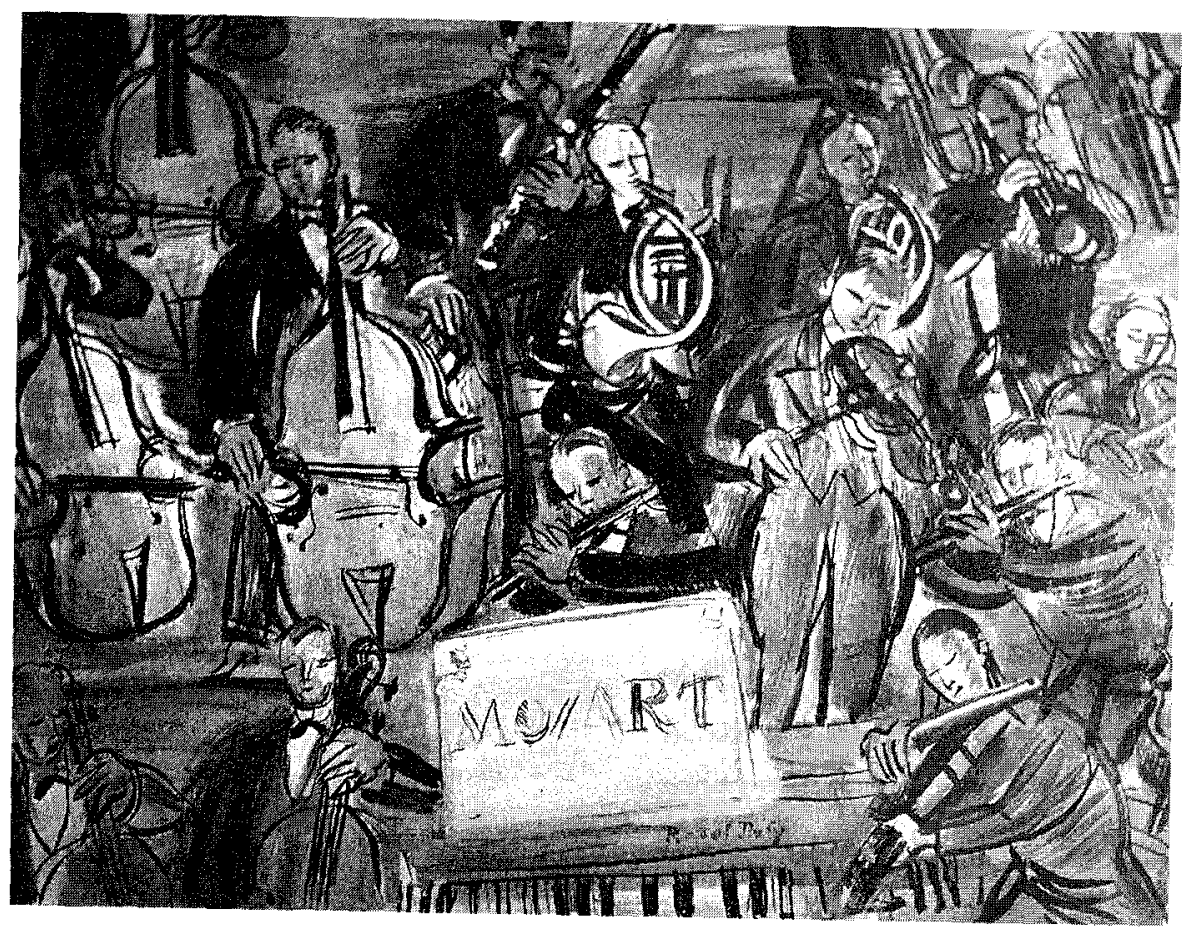

Lámina 6. Raoul Dufy (1877-1953). Mozart-Concierto, 1951. Óleo sobre lienzo. Localización Staatsgalerie, Stuttgart (Alemania).

Dufy nos presenta una visión personal de un concierto para violín y orquesta, probablemente uno de los conocidos conciertos para Violín y Orquesta de W.A. Mozart. En primer plano nos muestra todas las familias instrumentales incluyendo un piano sobre el que hay un cartel con la inscripción «Mozart». Esto es seguramente un homenaje al compositor que supo ampliar la reducida orquesta barroca y dar cabida a diversos instrumentos, sobre todo los de viento. El solista sostiene el violín de una manera muy personal (violín bajo, cabeza demasiado inclinada), motivado por el pasaje que interpreta. No es sólo el solista el que se concentra en la música: percibimos que todos ios músicos siguen atentos el desarrollo de la partitura. Dufy ha logrado transmitir al espectador su sensación ante un buen concierto. Un detalle: su admiración de Mozart no termina con el nombre del compositor. Los músicos disfrutan con su música. 


\section{CÓMO SE REPRESENTA EL VIOLINN}

Ferrari concibe su obra de manera muy global, pinta con sencillez y fuerza, pero también se recrea en detalles: es el narrador de una bonita historia y no quiere omitir nada. Es cierto que el violín es importante, a Gaudenzio le interesa ofrecer una detallada descripción del instrumento en su época, pero no es el centro de atención. Ropajes, rostros, anatomía... todo contribuye a la belleza global que transpiran su obras. Sólo hay que tomar, por ejemplo, los ángeles de La Madonna degli aranci para darse cuenta de que la serenidad que transmiten no es fruto de su personalidad propia sino del conjunto.

Sin embargo, se confiere un trato especial al violín, siempre en ese afán de mostrar al mundo un nuevo invento. De ahí que en ocasiones se descuide la perspectiva en favor del detalle: los pre-violines de La Madonna degli aranci y Adoración del Niño están torcidos hasta el punto de resultar imposible anatómicamente la ejecución musical. Putto con instrumento de arco muestra un instrumento similar a un violín pintado con todo el cuidado del mundo, ya que supone una forma poco común del instrumento.

Aunque parezca que en su obra prima el movimiento por encima de la depuración técnica, Dufy demuestra que hay meditación detrás de sus fantasías. Para conseguir el alto nivel de su "producción musical» sigue un patrón, que repite sistemáticamente. Puede observarse en MozartConcierto que para los primeros violines de la orquesta emplea suaves líneas ondulantes horizontales, para los segundos violines emplea la misma técnica en dirección opuesta, en los cellos predomina lo vertical, las violas están envueltas en una nebulosa, etc. Todo ello contribuye a crear una atmósfera y no un mero retrato de la realidad. El color también es muy importante, ya que puede expresar una sensación concreta. Guichard-Meili (Guichard-Meili, 1964) cree que la pintura tonal en Dufy adquiere un doble sentido: en cada cuadro domina un color, que representa una tonalidad musical.

Comparando El violinista (1937) y El violinista (1945) asistimos a la evolución personal de Dufy. Puesto que el violín tal y como él lo conoce lleva años con esa forma no hace falta detenerse en los detalles para que lo reconozca el público. Lo simplifica, reduciéndolo a sus características más atractivas: efes, cuello, curvas femeninas, voluta, de una manera que sólo alguien que conozca y quiera al instrumento puede hacer, ya que sus violines pueden tocarse a pesar de faltar tantas partes. 


\section{EL PROPÓSITO DEL ARTISTA}

Vivir del arte, es sabido, es difícil, por lo que hay que entender que a veces prime el gusto del cliente sobre la creatividad del artista: si se requiere un violín en la composición hay que tratar de incluirlo ${ }^{4}$. Afortunadamente no parece que este sea el caso con Ferrrari y Dufy; el incluir violines en varias obras y su interés por la música lo demuestran.

Algo tenían en mente al retratarlos. Ferrari sirve a la Iglesia, su principal cliente, pero el mimo con que trata los temas divinos hace pensar que tenía una inclinación personal por lo religioso, sin ser esto óbice para una mente típicamente renacentista. Sus violines son instrumentos para alabar al cielo.

Por otro lado, Dufy explora su propia creatividad. El ambiente musical en el que creció seguramente le llevó a querer reflejarlo en pintura. Su objetivo no es la glorificación, sino la exaltación de la música en sí. Las figuras serenas y devotas de la Adoración del Niño contrastan con el éxtasis y la pasión salvaje de los músicos en Mozart-Concierto.

\section{LO QUE SIGNIFICA PARA EL ARTISTA}

Podría decirse que Ferrari está enamorado del violín, demuestra una preferencia por él que se traduce en detalle y atención. La única pega es que sus violines no siguen un patrón, siendo difícil discernir si son violines o no ${ }^{5}$. Se da cuenta de que está naciendo un instrumento y profetiza su futura importancia al incluirlo en varias obras. Como no puede adivinar qué forma final adoptará, las pinta todas, convirtiéndose en esclavo de la realidad.

Dignifica la forma curva del violín que tanto le gusta al ponerlo en manos de ángeles. Como sugiere Winternitz (Winternitz, 1979), bien podría haber sido violinista y luthier, pues muestra un conocimiento profundo cuando incluye un violín en sus obras.

Tomando el ritmo como base, Dufy transforma el color en movimiento. Sus obras muestran ese joie de vivre que debió caracterizarle y su amor

\footnotetext{
4 Esto podría explicar la existencia de ciertas pinturas «inexactas» desde el punto de vista musical.

5 En la época convivian diversos instrumentos de cuerda que pueden confundirse con violines, cono la viola da bracio o el rebec, ya que, además, influyeron de una manera u otra en su evolución.
} 
por la música. El violín como instrumento es importante para Dufy; sintetiza el poder de la música y del hombre al crear esa belleza. Pero el violín cede el protagonismo al Hombre, si bien no como individuo: si le interesa es como un elemento de la vida y no se detiene en detalles que estropearían la composición global.

Sus violinistas no son autómatas sin alma, pero tampoco son individuos, aunque esto no signifique que carezcan de personalidad. Dufy consigue que el violín exprese un doble mensaje: la música y el Hombre. Pero es un mensaje velado. Los músicos no son más que la notas de una partitura, pero sus movimientos agitados y forma y sonido entrelazados se traducen maravillosamente en línea vibrante. Queda una impresión como reminiscencia de su etapa impresionista más que una narración.

\section{SU PAPEL EN LA OBRA}

En Ferrari el violín es un instrumento al servicio de la religión, visto en el contexto general de la obra. Así, se emplea en la Adoración del Niño para alabar al Niño Dios, en La Madonna degli aranci como compañía y deleite de la Virgen María, y en Putto con instrumento de arco vuelve a inscribirse en la simbología religiosa al ser tañido por un putto (angelote).

Dufy asigna un papel muy distinto a sus violines. No los asocia a un mismo significado ni los emplea en un contexto fijo. En las orquestas (Mozart-Concierto) el violín representa el arte en sí, la propia música. Carece de importancia como objeto, su papel es crear belleza. El inusitado detalle con que dibuja El violinista (1937) contrasta con su posterior tendencia fauvista. El violinista (1945) está más en su línea personal, pero el que retrate un individuo y no una masa (movimiento) indica que, o bien el tandem violín-violinista le interesa, o bien esto no es más que un estudio para futuras obras. Indagando en su producción observamos buen número de retratos, y además el violinista en cuestión tiene una técnica musical extraña, por lo que nos inclinamos por la primera hipótesis.

\section{SU PAPEL EN LA COMPOSICIÓN GLOBAL}

La cualidad suprema de la obra de Ferrrari es la extraordinaria vida que la empapa. El violín contribuye a la creación de una atmósfera armoniosa. El mimo con que se enfrenta a sus obra es notable: parece que oímos el crujir de las ricas vestimentas de los ángeles. Contrastando con Dufy, lo que oímos es delicado, suave, casi divino, no el poder sensual de 
la música en sí y por sí. La emoción y tensión de cada rostro y la sentida devoción contribuyen a la atmósfera pacífica de la Adoración del Niño, Putto con instrumento de arco y La Madonna degli aranci.

Dufy atrapa la música desde que empieza a crearse en los gestos de los músicos y el directo: casi consigue indicar el hilo invisible que los une. La expresión corporal, en particular de las caras, de El violinista (1937) y El violinista (1945) es de concentración y disfrute, de profundo gozo de la música. Sin embargo, Dufy viene a advertirnos de los peligros de dejarse llevar por la pasión en detrimento de la pureza técnica. Así, la atmósfera en Mozart-Concierto es tan cargada y tan tensa que los músicos abandonan sus conocimientos técnicos para deleitarse con lo que crean. El mismo solista se ha lanzado al placer olvidando el virtuosismo por un instante.

\section{LO QUE LAS OBRAS NOS DICEN SOBRE EL CONTEXTO SOCIO-CULTURAL.}

Una interpretación contextual de la obra de Ferrari y Dufy supone la comparación de los siglos XVI y Xx. En términos generales, desde el punto de vista artístico S. Xvı significa renacimiento, cinquecentto; principios S. XX supone ismos, art nouveau, impresionismo, cubismo... las mil y una posibilidades del arte. Históricamente hablando, el renacimiento es una revolución: el Nuevo Mundo, los inventos científicos, una nueva luz: el re-nacer tras la oscura Edad Media. La Iglesia mantiene la hegemonía de la época anterior, si bien se revisan posturas. Ferrari se aferra a la tradición y pinta temas religiosos (piadosas y dulces Vírgenes - La Madonna degli aranci-, el Nacimiento Adoración del Niño-). El siglo xx también conlleva una serie de transformaciones, aunque no precisamente cargadas de optimismo: dos Guerras Mundiales, una importante depresión económica, el crack del 29. Pues bien, a pesar de todo ello, Duify pintó El violinista (1945) tras haber vivido los horrores de la guerra, y no puede decirse que le afectara demasiado ${ }^{6}$.

Ferrari nos cuenta qué papel desempañaba la música entre las clases pudientes. Aunque no se saliera del contexto religioso ni retratara forma humana alguna ajena a la temática de la obra, sabemos que pintaba para las clases ricas, porque era la única capa social, junto con la Iglesia, capaz de costear los gastos (de ahí la práctica del mecenazgo). Puesto que el fin

\footnotetext{
${ }^{6}$ Francia estaba con los Aliados.
} 
de la pintura religiosa es glorificar a Dios y a la Iglesia, un rasgo dominante será forzosamente la grandeza: los voluminosos ropajes realzan el ideal de moda de la época.

El violín se estaba inventando durante el S. XV, las pinturas de Ferrari son la base de musicólogos para su evolución hasta nuestros días. Una caja de resonancia, cuatro cuerdas y un arco son los componentes básicos de un violín, todo lo demás es fantasía y preferencias acústicas del constructor. De ahí la variedad de modelos que retrata Ferrari, acaso alguno inventado por él pero plausible ( $P$ utto con instrumento de arco). La familia de las cuerdas se convirtió pronto en la predilecta de las clases altas como nos muestra. Los cuadros de la época de temas populares con instrumentos musicales tienden a ser instrumentos de viento, en especial la flauta travesera.

Dufy conoció el mismo violín que conocemos nosotros, ya que éste adoptó su forma definitiva en el S. XVII, época de los grandes luthiers: Guarnerius, Stradivarius, con mínimas variaciones posteriores. Las posibilidades del violín actual son infinitas, y el pintor francés, conocedor de esta maravilla, quiso reflejarlo. El violinista (1937) encarna la pureza del instrumento en su mejor momento. $Y$ eso sin contar el gran homenaje que le rinde al convertirle en el rey de su estudio ${ }^{7}$.

Las pinturas musicales nos proporcionan información acerca de los hábitos de tocar de la época. Al comparar Ferrari con Dufy, chocan las diferentes disposiciones de los músicos y sus distintas actitudes, pero ante todo sorprende su fin: los ángeles glorifican a Dios, los músicos contemporáneos viven de la música porque disfrutan con ella.

\section{IMPLICACIÓN DEL ARTISTA EN SU TRABAJO}

Podría asumirse que por estar tan sometido a la Iglesia Ferrari no gozaba de total libertad a la hora de elegir sus temas. Pero su reiterado interés por hablarnos del violín indica que no es del todo cierto. La curiosidad, diríase científica, le llevó a contarnos su historia, por lo que su obra se convierte en un documento en ese sentido. Estudió distintos tipos de violín pues todavía no existía un modelo: el pre-violín de Putto con instrumento de arco poco tiene que ver con el que aparece en la_Adoración del

7 Son muchos ios violines que se encuentran en la producción de Dufy ya sea en sus orquestas, sus retratos o sus naturalezas muertas. Consultar Laffaille, Op. cit. 
Niño, que debió ser una forma establecida, pues vuelve a salir en La Madonna degli aranci.

A Dufy le fascinaba el violín: hasta lo tocaba. ¿Por qué no cuidó más su representación, como Ferrari? Es cierto que pintó retratos individuales (El violinista (1937), El violinista (1945)), pero prefería la música como un todo y no sólo como un instrumento concreto, como fauve buscaba el movimiento de la vida. Cuentan que Mozart, el compositor al que tanto admiró Dufy, solía decir que «buscaba las notas que se aman»; el pintor Hans Hartung opina que Dufy busca los colores que se aman (ver GuichardMeili, 1964: 4). Bien podría ser esto cierto, pues la obra de Dufy es armónica donde las haya. Su pintura se acerca todo al máximo al sentimiento de la música (Mozart-Concierto).

\section{FINALE}

\section{Conclusiones}

Del análisis del tratamiento que Ferrari y Dufy confieren al violín se puede concluir:

a) A pesar de pertenecer a dos épocas diferentes y poseer, por tanto, mentalidades distintas, ambos artistas demuestran un alto concepto del violín.

b) El estilo de ambos pintores está condicionado por las ideas de su tiempo. Es decir, están sujetos a la interpretación global dentro de su siglo, aun conservando rasgos originales y personales. Visto así, Dufy viene a ser la evolución lógica de Ferrrari, ya que vivió cuatro siglos después. Su interpretación no es más que el resultado de una concepción distinta del Hombre: la religión en el renacimiento ocupaba un lugar destacado en la vida cotidiana, mientras que la modernidad incorpora elementos de libertad en un sentido más amplio.

c) El vínculo entre las obras de Ferrari aquí estudiadas es la música al servicio de la religión; el vínculo entre las de Dufy es la música como expresión del movimiento de la vida.

d) Dentro de las obras de Ferrrari, la búsqueda del detalle para «narrar" la evolución física del violín es una constante. Así, encontramos variedad de formas en La Madonna degli aranci, Putto con instrumento de arco y Adoración del Niño. Es, por tanto, una mirada objetiva y fría hacia el violín, más científica que apasionada. Las obras de Dufy, sin embargo, muestran una evidente evolución, si no de la estima del pintor hacia el vio- 
lín, sí de su concepción del mismo dentro del movimiento de la vida en el contexto del hombre. Se explica de esta manera que el detalle de El violinista (1937) contraste con su posterior visión de El violinista (1945), y más aún con los violines abocetados de Mozart-Concierto. No es sólo una evolución estilística, sino también una evolución paralela de su idea del violín.

La exactitud del retrato del violín depende de muchos factores. El artista está sometido a influencias que pueden interferir en su trabajo: de naturaleza psicológica, tradiciones de estilo o técnica, los soportes técnicos o el entorno social que le envuelve, de modo que es posible que el resultado final difiera no sólo de la realidad física del instrumento, sino incluso de la idea primitiva del autor. Lo que se conoce como prettyfication ${ }^{8}$ coloca al artista en el conflicto entre lo real y lo ideal. Las diferencias interpretativas se explican muchas veces por estos factores, las de Ferrari y Dufy no tenen por qué ser excepciones.

Sería preciso extender la investigación al conjunto de los violines en el arte de los siglos XVI y XX para poder ratificar y generalizar estas conclusiones; la puerta está abierta. Otro interrogante aún por resolver es si los violines de Ferrari son lo antecesores de los nuestros.

\section{BIBLIOGRAFÍA}

BENEZIT, E. (1976), Dictionaire des peintres, sculpteurs, dessinateurs et graveurs, París: Librairie Gründ

Benton, W. y Hemingway, H. (1974), The New Encyclopaedia Britannica, 15th edition, Chicago/London/Toronto/etc.: Encyclopaedia Britannica, Inc.

Catálogo de la exposición (1969) L'art et la musique, Burdeos: Galerie des Beaux Arts

Cogniat, R. (1977), Dufy, París: Flammarion

Guichard-Meill, J. (1964), Dufy: Música, Barcelona: Gustavo Gili

HALSEY, E. (1908), Gaudenzio Ferrari, Londres: G. Bell \& Sons

JUNOD, PH. (1988), La musique vue par les peintres, Lausanne: EDITA, S.A.

Revilla, F. (1990), Diccionario de iconografía, Madrid: Cátedra

SADIE, S. (1993), The New Grove Dictionary of Musical Instruments, London: Macmillan

WinTERnitz, E. (1979), Musical Instruments and Their Symbolism in Western Art. (Studies in Musical (conology), New Haven y Londres: Yale University Press

8 Prettyfication: término anglosajón que deriva del adjetivo pretty = bonito. Se refiere al embellecimiento inconsciente e idealista al que suelen tender los artistas. 
